\title{
Dysglycaemia and 90 day and 1 year risks of death or readmission in patients hospitalised for community-acquired pneumonia
}

\author{
D. T. Eurich • J. M. Gamble • T. J. Marrie • \\ S. R. Majumdar
}

Received: 23 June 2009 / Accepted: 8 October 2009 /Published online: 20 November 2009

(C) Springer-Verlag 2009

\begin{abstract}
Aims/hypothesis The aim of this study was to investigate whether dysglycaemia at admission is associated with adverse events at 90 days or 1 year in a population-based cohort of patients hospitalised with community-acquired pneumonia (CAP).

Methods Clinical and laboratory data were prospectively collected on all 2,366 adults without diabetes admitted with $\mathrm{CAP}$ to six hospitals in Edmonton (AB, Canada) and grouped according to admission glucose: 4.0 to $<6.1 \mathrm{mmol} / 1$ ( $n=778$, reference group), 6.1 to $<7.8 \mathrm{mmol} / \mathrm{l}(n=924) ; 7.8$ to $<11.1 \mathrm{mmol} / \mathrm{l}(n=535)$; and 11.1 to $20 \mathrm{mmol} / 1 \quad(n=129)$. Multivariable Cox models were used to examine the relationship between dysglycaemia and mortality or CAP readmission during follow-up.

Results The mean age was 69 (SD 18) years and $48 \%$ of participants were female. Compared with those with glucose $<6.1 \mathrm{mmol} / 1$ (114 [15\%] deaths), no differences in 90 day mortality were observed in the dysglycaemia groups: 143 deaths $(15 \%)$ in the $6.1-7.8 \mathrm{mmol} / 1$ group (adjusted HR [aHR] 0.92, 95\% CI 0.72-1.18), 111 deaths (21\%) in the $7.8-11.1 \mathrm{mmol} / 1$ group (aHR 1.05, 0.81-1.37) and 34 deaths $(26 \%)$ in the $11.1-20 \mathrm{mmol} / \mathrm{l}$ group (aHR $1.30,0.88-1.93)$. Similarly, compared with those in the $<6.1 \mathrm{mmol} / \mathrm{l}$ group (198 [25\%] deaths), no difference in
\end{abstract}

D. T. Eurich $(\bowtie) \cdot$ J. M. Gamble $\cdot$ S. R. Majumdar

Department of Public Health Sciences, School of Public Health,

University of Alberta,

13-103 Clinical Sciences Bldg,

Edmonton T6G 2G3 AB, Canada

e-mail: deurich@ualberta.ca

T. J. Marrie $\cdot$ S. R. Majumdar

Department of Medicine, Faculty of Medicine and Dentistry,

University of Alberta,

Edmonton, AB, Canada
1 year mortality was observed: 233 deaths $(25 \%)$ in the 6.1 to $<7.8 \mathrm{mmol} / 1$ group (aHR 0.86, 0.71-1.04), 164 deaths $(31 \%)$ in the 7.8 to $<11.1 \mathrm{mmol} / 1$ group (aHR $0.92,0.75-$ 1.14 ) and 49 deaths (38\%) in the 11.1 to $20 \mathrm{mmol} / \mathrm{l}$ group (aHR 1.12, 0.81-1.55). Readmissions for CAP were also similar at 1 year: compared with $10 \%(70 / 707)$ in the $6.1 \mathrm{mmol} / 1$ group, the frequencies were $8 \%(66 / 842), 9 \%$ $(45 / 474)$ and $10 \%(11 / 107)$ in the 6.1 to $<7.8 \mathrm{mmol} / 1,7.8$ to $<11.1 \mathrm{mmol} / \mathrm{l}$, and 11.1 to $20 \mathrm{mmol} / \mathrm{l}$ groups, respectively ( $p>0.05$ for all comparisons).

Conclusions/interpretation Although previously associated with inpatient morbidity and mortality, admission dysglycaemia was not associated with an increased risk of death or CAP readmission at 90 days or 1 year among those who survived hospitalisation for pneumonia.

Keywords Diabetes · Glucose $\cdot$ Health outcomes

Pneumonia $\cdot$ Prospective cohort

$\begin{array}{ll}\text { Abbreviations } \\ \text { aHR } & \text { Adjusted HR } \\ \text { CAP } & \text { Community-acquired pneumonia } \\ \text { COPD } & \text { Chronic obstructive pulmonary disease } \\ \text { PSI } & \text { Pneumonia severity index } \\ \text { uHR } & \text { Unadjusted HR }\end{array}$

Introduction

Community-acquired pneumonia (CAP) is a common and costly condition, with over $\$ 9$ billion spent annually in the US [1] where it is also the most common cause of infectionrelated mortality [2]. Mortality rates due to CAP have not decreased significantly in recent years and hospitalisations 
have actually increased [3]. Although prognostic factors for adverse outcomes in CAP patients have been identified [4], dysglycaemia (that is, glucose values outside of the normal range) at hospital admission has been relatively underappreciated. Indeed, the pneumonia severity index (PSI), a validated measure of the severity of illness at CAP presentation, does not differentiate among individuals with dysglycaemic values under $14 \mathrm{mmol} / \mathrm{l}$ and considers those with measurements of 14 to $20 \mathrm{mmol} / \mathrm{l}$ to be at equivalent risk [5].

Increasing evidence suggests that admission dysglycaemia is a strong independent and potentially modifiable prognostic factor for adverse short-term outcomes in a wide range of conditions, including acute myocardial infarction [6], stroke [7], trauma [8], surgery [9], chronic obstructive pulmonary disease (COPD) [10] and pneumonia [11]. In patients with CAP, dysglycaemia upon hospital admission has been independently associated with adverse in-hospital outcomes including mortality and acute complications [12]. This relationship seems robust and appears independent of the presence or absence of diabetes $[4,11,13]$.

Importantly, however, the independent effect of admission glucose levels on longer-term outcomes in patients with CAP is less certain. In a case-control study from Denmark, increasing dysglycaemia in patients with diabetes was associated with an increasing risk of admission for CAP, although the effects in CAP patients without diabetes were not assessed [14]. In the only other study, also from Denmark, dysglycaemia on admission for pneumonia was a strong predictor of 30 day mortality in both patients with and without diabetes [11]. Both studies were limited, however, because of a lack of some important clinical prognostic data known to affect outcomes in patients with CAP (e.g. functional status, validated measures of pneumonia severity). Therefore, we designed our study to overcome these limitations and examined the association between admission dysglycaemia and longer-term adverse events in a clinically rich prospective population-based cohort of patients without diabetes who were hospitalised with CAP. We specifically examined mortality at 90 days and death or readmission for pneumonia at 1 year.

\section{Methods}

Participants and setting The population-based cohort and data-collection methods have been previously described in detail [15-17]. Briefly, data were prospectively collected on all patients $>17$ years of age admitted with CAP to all six hospitals in Edmonton, AB, Canada between 2000 and 2002 and treated according to a validated clinical pathway for CAP [17, 18]. Trained research nurses prospectively collected data using standardised abstraction forms that included clinical characteristics of patients (demographics, comorbidities, smoking, pre-morbid functional status and laboratory data) and use of prescription medications in the week prior to admission. Further, the PSI-a validated measure of the severity of illness at presentation-was determined $[5,15,16]$. Individuals were excluded if they had tuberculosis, cystic fibrosis or were immunocompromised or pregnant. All participants provided written informed consent and the University of Alberta Health Research Ethics Board approved the study.

Participants were subsequently followed for over 5 years post discharge through linkage to provincial administrative databases [17]. These databases maintain current demographic, vital statistics and health-services data on all registrants [17]. Trained health records administrators conduct all diagnostic coding and accuracy is routinely validated through provincial and central Canadian agencies [17].

Study sample The source population consisted of all participants with a casual blood glucose measurement drawn as part of a standard panel of venous blood work indicated by a regional clinical treatment pathway at the time of hospital admission. Although single casual glucose levels of $<11.1 \mathrm{mmol} / 1$ are within the 'normal' range [19], previous studies suggest that casual glucose levels $>6.1 \mathrm{mmol} / 1$ are associated with adverse outcomes in CAP patients $[11,12]$. Thus, as have others $[11,14,20]$, we classified participants a priori according to admission glucose levels into four levels of dysglycaemia: 4.0 to $<6.1 \mathrm{mmol} / \mathrm{l} ; 6.1$ to $<7.8 \mathrm{mmol} / 1 ; 7.8$ to $<11.1 \mathrm{mmol} / \mathrm{l}$; and 11.1 to $20.0 \mathrm{mmol} / \mathrm{l}$. Participants with admission glucose levels greater than $20 \mathrm{mmol} / 1$ or less than $4 \mathrm{mmol} / 1$ [19] were excluded $(n=538)$ as such extreme glucose levels would mandate urgent hospital management, resulting in data inexorably confounded by treatment modality (i.e. outcomes observed related to in-hospital care as opposed to glucose per se) [12]. Further, adult patients with known diabetes, defined as a documented history or treatment with oral glucose-lowering agents or insulin, were excluded [11, 14]. Finally, 91 (4\%) participants who could not successfully be linked to our administrative databases were excluded.

Outcomes Our primary outcome, defined a priori, was death from any cause within 90 days following hospital admission [11]. To evaluate the potential longer-term impact of admission dysglycaemia, we also evaluated death from any cause occurring within 1 year. Additionally, the long-term impact of admission dysglycaemia on non-fatal adverse events was evaluated. Specifically, we evaluated rehospitalisations for CAP within 1 year, defined as a hospital readmission with a most responsible discharge diagnosis of 
480-487.7 (International Classification of Diseases, 9th Revision, Clinical Modification [ICD-9-CM] values) or $\mathrm{J} 10.0$, J11.0, J12-J18 (International Classification of Diseases, 10th Revision, Canada [ICD-10-CA] values), according to dysglycaemic levels [17, 21, 22]. These ICD diagnostic codes are highly accurate (98\% sensitivity and $97 \%$ specificity) for the identification of pneumonia compared with medical charts [3, 23, 24].

Statistical analysis Cox proportional hazards regression models were used to assess the relationship between admission dysglycaemia and outcomes. Participants with admission glucose levels of 4.0 to $<6.1 \mathrm{mmol} / 1$ served as reference group for all analyses. Potentially confounding variables included in the multivariable models included age, sex, comorbidities (cardiovascular disease or stroke, neoplasm, chronic obstructive pulmonary disease), total number of prescription medications, clinical characteristics (e.g. advanced directives, smoking status, nursing-home residence, immunisation history, pre-morbid functional status [defined as independent in ambulation vs consistently needing some type of walking-aid or a wheelchair vs bedridden]) and the PSI $[15,16]$. As the PSI score accounts for admission hyperglycaemia $(+10$ for patients with glucose $\geq 14 \mathrm{mmol} / \mathrm{l}$ ) [5], we excluded this criterion and recalculated the PSI score for every patient. All participants were followed until event of interest or death, health insurance coverage termination or 31 March 2006. All analyses were completed with Stata IC, version 10 (Stata, College Station, TX, USA).

Sensitivity analyses To evaluate the robustness of our models, we pre-specified several sensitivity analyses. First, we further adjusted for drug therapies known to affect glucose levels (e.g. oral corticosteroids, diuretics, betablockers, antipsychotics) and additional comorbidities including a history of alcoholism [25], and mental health disorders [26]. Second, to ensure our models were not overfitted, we built a more parsimonious model that included only those variables with a $p$ value $<0.1$ in the final multivariable model. Third, although we are interested in the effects of dysglycaemia in patients without diabetes, in a sensitivity analysis we included patients with known history of diabetes $(n=402)$ in the study sample and evaluated the interaction between diabetes status and dysglycaemia levels on mortality.

\section{Results}

Of the 2,366 patients without diabetes who formed our study sample, the mean age was 69 years (SD 18), 1,142 $(48 \%)$ were female, $432(18 \%)$ were nursing-home residents, 1,454 (61\%) had severe class IV/V pneumonia according to the modified PSI and mean follow-up was 2.8 years (SD 1.8) (Table 1). Fully two-thirds of the cohort had dysglycaemia at admission: 924 participants $(39 \%)$ had levels between 6.1 and $<7.8 \mathrm{mmol} / \mathrm{l}, 535$ (23\%) had levels between 7.8 and $<11.1$, and 129 participants $(5 \%)$ had levels between 11.1 and $20.0 \mathrm{mmol} / 1$. Overall, increasing levels of dysglycaemia were associated with increasing age and frailty, as well as more severe pneumonia (Table 1).

All-cause mortality at 90 days At 90 days, compared with the 114 deaths in those with an admission glucose of 4.0 to $<6.1 \mathrm{mmol} / 1(15 \%)$, there were 143 deaths $(15 \%$, unadjusted HR [uHR] 1.07, 95\% CI 0.84-1.37) in those with an admission glucose of 6.1 to $7.8 \mathrm{mmol} / \mathrm{l}, 111$ deaths $(21 \%$, uHR $1.48,1.14-1.92)$ in the 7.8 to $<11.1 \mathrm{mmol} / 1$ group, and 34 deaths (26\%, uHR 1.98, 95\% CI 1.35-2.91) in the 11.1 to $20.0 \mathrm{mmol} / \mathrm{l}$ group. After controlling for age, sex, comorbidities, total number of prescription medications and clinical characteristics, we found no association between glucose levels of 6.1 to $7.8 \mathrm{mmol} / 1$ (adjusted HR [aHR]) 0.92 , 95\% CI 0.72-1.18), 7.8 to $<11.1 \mathrm{mmol} / 1$ (aHR 1.05, $0.81-$ 1.37 ) or 11.1 to $20.0 \mathrm{mmol} / \mathrm{l}$ (aHR $1.30,0.88-1.93$ ) and 90 day mortality compared with participants with an admission glucose $<6.1 \mathrm{mmol} / \mathrm{l}$ (Fig. 1, Table 2).

As elevated glucose values may be related to other commonly measured markers of CAP severity included in the PSI, we excluded the PSI from our multivariable models. Compared with those with glucose levels $<6.1 \mathrm{mmol} / 1$, no difference in risk of death at 90 days was observed in those with an admission glucose of 6.1 to $<7.8 \mathrm{mmol} / \mathrm{l}$ (aHR 0.92, 0.72-1.18) nor with an admission glucose of 7.8 to $<11.1 \mathrm{mmol} / \mathrm{l}$ (aHR 1.13, 0.87-1.48). A significant increased risk of 90 day mortality was observed, however, in those with admission glucose in the highest range, $11.1-20.0 \mathrm{mmol} / \mathrm{l}$ (aHR 1.53, 1.03-2.26).

All-cause mortality at 1 year Compared with those with an admission glucose of $<6.1 \mathrm{mmol} / 1$ (198 [25\%] deaths), no difference in risk of death at 1 year was observed: 233 deaths $(25 \%)$ with an admission glucose of 6.1 to $<7.8 \mathrm{mmol} / \mathrm{l}$ (aHR 0.86, 0.71-1.04), 164 deaths (31\%) with an admission glucose of 7.8 to $<11.1 \mathrm{mmol} / \mathrm{l}$ (aHR 0.92 , $0.75-1.14)$ and 49 deaths $(38 \%)$ with an admission glucose of 11.1-20 mmol/l (aHR 1.12, 0.81-1.55) (Table 2).

CAP readmission at 1 year Of the 2,130 (90\%) participants with admission glucose who were discharged alive from hospital, by 1 year, compared with the $10 \%$ of participants rehospitalised for CAP in the $<6.1 \mathrm{mmol} / 1$ group (70/707), $8 \%$ of individuals were re-hospitalised in the 6.1 to $<7.8 \mathrm{mmol} / 1$ group (66/842), $9 \%$ in the 7.8 to $<11.1 \mathrm{mmol} / 1$ group $(45 / 474)$ 
Table 1 Cohort characteristics

\begin{tabular}{|c|c|c|c|c|c|}
\hline \multirow[t]{2}{*}{ Characteristic } & \multicolumn{5}{|c|}{ Admission glucose $(\mathrm{mmol} / \mathrm{l})$} \\
\hline & 4.0 to $<6.1(n=778)$ & 6.1 to $<7.8(n=924)$ & 7.8 to $<11.1(n=535)$ & 11.1 to $20.00(n=129)$ & $p$ value \\
\hline Age (years) & $64 \pm 20$ & $70 \pm 18$ & $72 \pm 16$ & $74(15)$ & $<0.001$ \\
\hline Sex (female) & $376(48)$ & $438(47)$ & $256(48)$ & $72(56)$ & 0.354 \\
\hline \multicolumn{6}{|l|}{ Previous comorbidities } \\
\hline Cardiovascular disease & $270(35)$ & $378(41)$ & $233(44)$ & $60(47)$ & 0.002 \\
\hline Neoplasm & $124(16)$ & $135(15)$ & $81(15)$ & $18(14)$ & 0.866 \\
\hline COPD & $235(30)$ & $290(31)$ & $181(34)$ & $43(33)$ & 0.547 \\
\hline \multicolumn{6}{|l|}{$\mathrm{PSI}^{\mathrm{a}}$} \\
\hline Class I or II & $203(26)$ & $173(19)$ & $68(13)$ & $16(12)$ & \multirow[t]{4}{*}{$<0.001$} \\
\hline Class III & $153(20)$ & $190(21)$ & $98(18)$ & $11(9)$ & \\
\hline Class IV & $273(35)$ & $368(40)$ & $224(42)$ & $63(49)$ & \\
\hline Class V & 149 (19) & $193(21)$ & $145(27)$ & $39(30)$ & \\
\hline \multicolumn{6}{|l|}{ Premorbid functional status } \\
\hline Independent mobility & $707(91)$ & $839(91)$ & $465(87)$ & $108(84)$ & \multirow[t]{3}{*}{$<0.001$} \\
\hline Wheelchair/prosthesis & $56(7)$ & $46(5)$ & $37(7)$ & $9(7)$ & \\
\hline Bedridden & $15(2)$ & $39(4)$ & $33(6)$ & $12(9)$ & \\
\hline \multicolumn{6}{|l|}{ Smoking status } \\
\hline Non-smoker & $313(40)$ & $385(42)$ & $223(42)$ & $71(55)$ & \multirow[t]{3}{*}{$<0.001$} \\
\hline Former smoker & $217(28)$ & $314(34)$ & $195(36)$ & $38(29)$ & \\
\hline Current smoker & $248(32)$ & $225(24)$ & $117(22)$ & $20(16)$ & \\
\hline Pneumococcal vaccination & $161(21)$ & $224(24)$ & $128(24)$ & $31(24)$ & 0.324 \\
\hline Advanced directives & $61(8)$ & $95(10)$ & $79(15)$ & $24(19)$ & $<0.001$ \\
\hline Nursing-home resident & $113(15)$ & $165(18)$ & $123(23)$ & $31(24)$ & $<0.001$ \\
\hline Five or more medications & $97(12)$ & $135(15)$ & $98(18)$ & $22(17)$ & 0.028 \\
\hline
\end{tabular}

Data are presented as mean $\pm \mathrm{SD}$ or $n(\%)$

${ }^{a}$ PSI score and subsequent risk class modified by omission of points for admission hyperglycaemia ( $\left.\geq 14 \mathrm{mmol} / \mathrm{l}\right)$

and $10 \%$ in the 11.1 to $20.0 \mathrm{mmol} / \mathrm{l}$ group $(11 / 107)$. Multivariable analyses demonstrated no significant association between admission glucose and CAP re-hospitalisations (Table 2).

Fig. 1 Sequentially adjusted models of the association between dysglycaemic category and 90 day mortality. Note: 4.0 to $<6.1 \mathrm{mmol} / 1$ is the reference category
Sensitivity analyses The risk of death at 90 days associated with dysglycaemia was nearly identical to our main results even after adjusting for drug therapies known to affect glycaemic levels and including additional comorbidities in

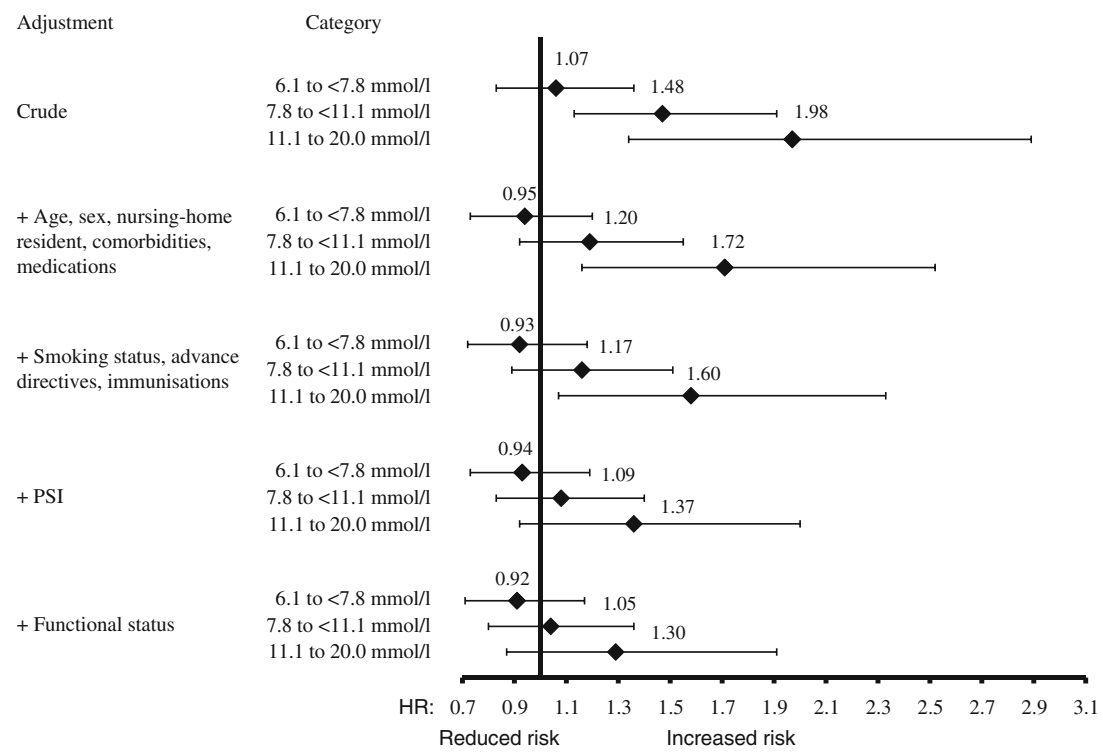


Table 2 Adjusted hazard ratios (95\% CI) from multivariable Cox proportional hazards models

${ }^{\text {a }}$ Reference group

\begin{tabular}{|c|c|c|c|}
\hline \multirow[t]{2}{*}{ Glucose category } & \multicolumn{2}{|l|}{ Mortality } & \multirow{2}{*}{$\frac{\text { CAP readmission }}{1 \text { year }}$} \\
\hline & 90 days & 1 year & \\
\hline 4.0 to $<6.1 \mathrm{mmol} / 1^{\mathrm{a}}$ & 1 & 1 & 1 \\
\hline 6.1 to $<7.8 \mathrm{mmol} / 1$ & $0.92(0.72-1.18)$ & $0.86(0.71-1.04)$ & $0.74(0.53-1.04)$ \\
\hline 7.8 to $<11.1 \mathrm{mmol} / 1$ & $1.05(0.81-1.37)$ & $0.92(0.75-1.14)$ & $0.85(0.58-1.25)$ \\
\hline 11.1 to $20.0 \mathrm{mmol} / 1$ & $1.30(0.88-1.93)$ & $1.12(0.81-1.55)$ & $0.92(0.48-1.76)$ \\
\hline
\end{tabular}

our multivariate model: aHR $(95 \% \mathrm{CI})$ was $0.95(0.73-$ 1.22 ) for the 6.1 to $<7.8 \mathrm{mmol} / \mathrm{l}$ group, $1.07(0.82-1.40)$ for the 7.8 to $<11.1 \mathrm{mmol} / \mathrm{l}$ group and $1.37(0.92-2.05)$ for the 11.1 to $20.0 \mathrm{mmol} / 1$ group, compared with those with an admission glucose $<6.1 \mathrm{mmol} / \mathrm{l}$. In addition, models limited to known prognostic factors in patients with CAP (age, sex, functional status, PSI, advanced directives, nursing-home status, total medications, vaccines, smoking status, neoplasm, history of renal or liver disease, HIV status, alcoholism and immunosuppressive therapies), did not materially alter our results: aHR $(95 \% \mathrm{CI})$ was $0.95(0.73$ to 1.22$)$ for the 6.1 to $<7.8 \mathrm{mmol} / \mathrm{l}$ group, $1.08(0.83-1.41)$ for the 7.8 to $<11.1 \mathrm{mmol} / \mathrm{l}$ group and $1.39(0.93-2.06)$ for the 11.1 to $20.0 \mathrm{mmol} / \mathrm{l}$ group, compared with those with an admission glucose $<6.1 \mathrm{mmol} / \mathrm{l}$. Similarly, more parsimonious models that included only age, functional status, PSI, neoplasm, vaccinations, advanced directives, total medications and nursing-home status, yielded results comparable with our main analyses: aHR $(95 \% \mathrm{CI})$ was $0.93(0.72-$ $1.19)$ for the 6.1 to $<7.8 \mathrm{mmol} / \mathrm{l}$ group, $1.05(0.81-1.37)$ for the 7.8 to $<11.1 \mathrm{mmol} / 1$ group, and $1.28(0.87-1.90)$ for the 11.1 to $20.0 \mathrm{mmol} / 1$ group, compared with those with an admission glucose $<6.1 \mathrm{mmol} / \mathrm{l}$. Analyses that included patients with known diabetes $(n=402)$ gave results that were again nearly identical for death at 90 days (aHR 0.92 , 1.11 and 1.36 for the 6.1 to $<7.8 \mathrm{mmol} / \mathrm{l}, 7.8$ to $<11.1 \mathrm{mmol} / 1$ and 11.1 to $20.0 \mathrm{mmol} / \mathrm{l}$ groups, respectively $[p>0.05$ for all]). Furthermore, no statistically significant interaction between prior diabetes status and dysglycaemia levels ( $p$ value for interaction $>0.6$ ) existed, suggesting our results are consistent across patients. Of note, prior history of diabetes was not a significant predictor of 90 day mortality in our multivariate model $(p>0.05)$.

\section{Discussion}

Fully two-thirds of our adult cohort without known diabetes and CAP had admission dysglycaemia. We found that dysglycaemia was neither associated with an increased risk of mortality at 90 days nor with death or readmission to hospital for pneumonia at 1 year. Alternatively, because our estimate of 90 day mortality associated with the highest dysglycaemic category is non-significantly elevated (adjusted
HR 1.30 [0.88-1.93]), our data could still be interpreted by some as demonstrating persistent harm associated with admission dysglycaemia.

Our results are not consistent with two previous related studies by Danish researchers that reported a relationship between admission dysglycaemia and increased CAP hospitalisations and mortality. In the first study, Kornum et al. [14] reported an increased risk of admission for CAP associated with increasing dysglycaemia in patients with diabetes compared with those without diabetes using a large administrative database. In the second study, Kornum et al. reported that admission dysglycaemia was associated with increased mortality in patients without diabetes at 30 and 90 days (although 90 day data were not reported) [11]. In adjusted analyses, those with the highest glucose levels had an approximately twofold increased risk of death at 30 days when compared with patients without diabetes and admission glucose levels $\leq 6 \mathrm{mmol} / \mathrm{l}$.

Although the reasons for discrepancies between the results of Kornum et al. and our group are unknown, it is possible that the previous studies were affected by confounding related to the lack of detailed clinical information, as such information was difficult to capture and remained unmeasured. Indeed, despite small differences in reference categories among their studies and ours, the unadjusted data is fairly consistent in suggesting an increase risk of adverse outcomes with increasing dysglycaemia. Nevertheless, multivariable adjustment had little effect on the point estimates in the Kornum studies [11, 14] whereas our multivariable adjustments markedly attenuated the strength and statistical significance of the relationship between dysglycaemia and adverse events. Most notably, we were able to adjust for functional status and the wellvalidated PSI (based on three demographic variables, five comorbidities, five physical findings and six laboratory tests). Both are known to be highly predictive of adverse outcomes in CAP patients $[15,16]$. In fact, exclusion of the PSI from our multivariable models suggests that CAP patients with the highest level of dysglycaemia (11.1 to $20.0 \mathrm{mmol} / \mathrm{l}$ ) have a significantly increased risk of 90 day mortality compared with those with blood glucose $<6.1 \mathrm{mmol} / \mathrm{l}$ (aHR 1.53, 95\% CI 1.03-2.26). Moreover, omitting functional status from our analyses further increased this risk (aHR 1.60, 1.08-2.35) to values nearly 
identical to the previous reports $[11,14]$. As other markers of severe pneumonia within the PSI may also be correlated with dysglycaemia (e.g. falsely low measures of serum sodium because of elevated glucose levels), it is possible that adjustment for the PSI attenuated estimates of the effect of dysglycaemia on mortality; it is important to reflect, however, that the PSI itself may better be considered a measure of chronic ill health and susceptibility to death than a true marker of pneumonia 'severity' [17, 18]. Indeed, many of the variables within this index predate development of pneumonia and by their relative scoring, age, sex and comorbidities are the major drivers of the PSI score as compared with laboratory markers of severe pneumonia (i.e. hyponatraemia, azotemia and dysglycaemia) which may themselves be intercorrelated.

Our results must be viewed in light of several limitations. First, a lack of data on changes in blood glucose during hospitalisation limited us to using admission glucose. In the setting of CAP, no studies have been conducted to determine how best to characterise 'glucometrics' during hospital admissions. Although measures of persistently elevated glucose during hospitalisation may perform marginally better in predicting mortality than a single admission glucose in other disease states (most notably acute coronary syndromes), the measures are in fact highly correlated (correlation coefficient 0.8) [20]. Further, although a significant proportion of individuals admitted with pneumonia had dysglycaemia on admission, the proportion diagnosed with diabetes during the follow-up is unknown and additional study may be warranted. Second, administrative data were used to identify recurrent CAP events. Although some misclassification may have occurred, the ICD codes used have very high sensitivity and specificity for CAP-related hospital admissions [23, 24]. Third, our results may not necessarily be generalised to broader population-based studies that tend to include healthier and lower-risk patients with pneumonia who never become ill enough to require hospital admission and may not be followed as closely post discharge.

In conclusion, although increasing evidence demonstrates a strong association between admission dysglycaemia and adverse events during hospitalisation for CAP and other acute conditions, our longer-term study in those who survived their initial hospitalisation for pneumonia demonstrates no clinically important association between admission dysglycaemia and morbidity or mortality at 90 days or 1 year. In aggregate, these findings suggest that dysglycaemia is more likely to be a marker of pneumonia severity than a distinct target for therapy that may improve outcomes.

Acknowledgements An establishment grant from Alberta Heritage Foundation for Medical Research (AHFMR); grants-in-aid from Capital Health; and unrestricted grants from Abbott Canada, Pfizer
Canada and Janssen-Ortho Canada (all to T. J. Marrie); an operating grant from the Canadian Institutes of Health Research (CIHR) (200809MOP-191604). D. T. Eurich and S. R. Majumdar receive salary support awards from AHFMR, and D. T. Eurich also receives salary support from CIHR. J. M. Gamble holds a CIHR doctoral award and a full-time health research studentship through the AHFMR.

Duality of interest The authors declare that there is no duality of interest associated with this manuscript.

\section{References}

1. Lave JR, Lin CJ, Fine MJ, Hughes-Cromwick P (1999) The cost of treating patients with community-acquired pneumonia. Semin Respir Crit Care Med 20:189-197

2. Glover ML, Reed MD (2005) Lower respiratory tract infections. In: DiPiro JT, Talbert RL, Yee GC, Matzke GR, Wells BG, Posey ML (eds) Pharmacotherapy: a pathophysiologic approach, 6th edn. McGraw-Hill, New York, pp 1943-1962

3. Thomsen RW, Riis A, Nørgaard M et al (2006) Rising incidence and persistently high mortality of hospitalized pneumonia: a 10-year population-based study in Denmark. J Intern Med (GBR) 259:410-417

4. Fine MJ, Smith MA, Carson CA et al (1996) Prognosis and outcomes of patients with community-acquired pneumonia. A meta-analysis. JAMA 275:134-141

5. Fine MJ, Auble TE, Yealy DM et al (1997) A prediction rule to identify low-risk patients with community-acquired pneumonia. $\mathrm{N}$ Engl J Med 336:243-250

6. Goldberg RJ, Kramer DG, Lessard D, Yarzebski J, Gore JM (2007) Serum glucose levels and hospital outcomes in patients with acute myocardial infarction without prior diabetes: a community-wide perspective. Coron Artery Dis 18:125-131

7. Poppe AY, Majumdar SR, Jeerakathil T et al (2009) Admission hyperglycemia predicts a worse outcome in stroke patients treated with intravenous thrombolysis. Diabetes Care 32:617-622

8. Yendamuri S, Fulda GJ, Tinkoff GH (2003) Admission hyperglycemia as a prognostic indicator in trauma. J Trauma 55:33-38

9. McAlister FA, Man J, Bistritz L, Amad H, Tandon P (2003) Diabetes and coronary artery bypass surgery: An examination of perioperative glycemic control and outcomes. Diabetes Care 26: $1518-1524$

10. Baker EH, Janaway CH, Philips BJ et al (2006) Hyperglycaemia is associated with poor outcomes in patients admitted to hospital with acute exacerbations of chronic obstructive pulmonary disease. Thorax 61:284-289

11. Kornum JB, Thomsen RW, Riis A, Lervang HH, Schonheyder HC, Sorensen HT (2007) Type 2 diabetes and pneumonia outcomes: a population-based cohort study. Diabetes Care 30:22512257

12. McAlister FA, Majumdar SR, Blitz S, Rowe BH, Romney J, Marrie TJ (2005) The relation between hyperglycemia and outcomes in 2, 471 patients admitted to the hospital with community-acquired pneumonia. Diabetes Care 28:810-815

13. Falguera M, Pifarre R, Martin A, Sheikh A, Moreno A (2005) Etiology and outcome of community-acquired pneumonia in patients with diabetes mellitus. Chest 128:3233-3239

14. Kornum JB, Thomsen RW, Riis A, Lervang HH, Schonheyder HC, Sorensen HT (2008) Diabetes, glycemic control, and risk of hospitalization with pneumonia: a population-based case-control study. Diabetes Care 31:1541-1545

15. Marrie TJ, Wu L (2005) Factors influencing in-hospital mortality in community-acquired pneumonia: a prospective study 
of patients not initially admitted to the ICU. Chest 127:12601270

16. Majumdar SR, McAlister FA, Eurich DT, Padwal RS, Marrie TJ (2006) Statins and outcomes in patients admitted to hospital with community acquired pneumonia: population based prospective cohort study. BMJ 333:999-1001

17. Johnstone J, Eurich DT, Majumdar SR, Jin Y, Marrie TJ (2008) Long-term morbidity and mortality after hospitalization with community-acquired pneumonia: a population-based cohort study. Medicine (Baltimore) 87:329-334

18. Eurich DT, Marrie TJ, Johnstone J, Majumdar SR (2008) Mortality reduction with influenza vaccine in patients with pneumonia outside "flu" season: Pleiotropic benefits or residual confounding? Am J Respir Crit Care Med 178:527-533

19. Canadian Diabetes Association Clinical Practice Guidelines Expert Committee (2008) Canadian Diabetes Association 2008 Clinical Practice Guidelines for the Prevention and Management of Diabetes in Canada. Can J Diabetes 32:S1-S201

20. Kosiborod M, Inzucchi SE, Krumholz HM et al (2008) Glucometrics in patients hospitalized with acute myocardial infarction: defining the optimal outcomes-based measure of risk. Circulation 117:1018-1027
21. National Center for Health Statistics (NCHS) and the Centers for Medicare \& Medicaid Services (CMS) (2009) The International Classification of Diseases, 9th Revision, Clinical Modification (ICD-9-CM), 6th edn. http://icd9cm.chrisendres.com/index.php; accessed 26 October 2009

22. World Health Organization (2009) International Statistical Classification of Diseases and Related Health Problems 10th Revision, Version for 2007. Available from http://apps.who.int/classifications/ apps/icd/icd10online/; accessed 26 October 2009

23. Skull SA, Andrews RM, Byrnes GB et al (2008) ICD-10 codes are a valid tool for identification of pneumonia in hospitalized patients aged $\geq 65$ years. Epidemiol Infect 136:232-240

24. Aronsky D, Haug PJ, Lagor C, Dean NC (2005) Accuracy of administrative data for identifying patients with pneumonia. Am J Med Qual 20:319-328

25. Howard AA, Arnsten JH, Gourevitch MN (2004) Effect of alcohol consumption on diabetes mellitus: a systematic review. Ann Intern Med 140:211-219+I72

26. Knol MJ, Twisk JWR, Beekman ATF, Heine RJ, Snoek FJ, Pouwer F (2006) Depression as a risk factor for the onset of type 2 diabetes mellitus. A meta-analysis. Diabetologia 49:837845 